\title{
FRANCISCO GINER Y EL DESCUBRIMIENTO MODERNO DEL PAISAJE DE ESPAÑA
}

\author{
Nicolás Ortega CANTERo \\ Universidad Autónoma de Madrid
}

\section{Resumen}

Francisco Giner de los Ríos (1839-1915), fundador en 1876 de la Institución Libre de Enseñanza, inició, en los últimos decenios del siglo XIX, un verdadero descubrimiento del paisaje de España. Planteó una nueva visión del paisaje español, que incorporó la perspectiva del paisajismo geográfico moderno, inicialmente promovido por Humboldt. Esta nueva perspectiva atribuyó a ese paisaje un conjunto de valores culturales que se consideraron expresivos de la propia historia y de la identidad colectiva o nacional derivada de ella. Giner y sus colaboradores de la Institución Libre de Enseñanza vieron en el paisaje español (y sobre todo en el paisaje de Castilla y la Sierra de Guadarrama) un verdadero símbolo nacional.

Palabras clave: Francisco Giner de los Ríos; paisajismo geográfico moderno; paisaje español; Castilla; Sierra de Guadarrama.

\begin{abstract}
Francisco Giner de los Ríos (1839-1915), a founder in 1876 of the Institución Libre de Enseñanza, initiated, in the last decades of 19th century, a true discovery of the landscape of Spain. He proposed a new vision of the Spanish landscape, which incorporated the perspective of modern geographical landscaping as pioneered by Humboldt. This new perspective attributed to that landscape a cultural value set that was considered reflective of the Spanish history and of the collective or national identity derived from it. Giner and his colleagues of the Institución Libre de Enseñanza understood the landscape of Spain (and especially the landscape of Castilla and the Sierra de Guadarrama) as a real national symbol.
\end{abstract}

Keywords: Francisco Giner de los Ríos; modern geographical landscape's view; Spanish landscape; Castilla; Sierra de Guadarrama. 


\section{Introducción}

Recuerda Alfonso Reyes, en uno de los breves relatos de sus Simpatías y diferencias, una noche de fin de año que pasó, con Américo Castro y Antonio Solalinde, en la Sierra de Guadarrama. Se alojaron en el chalet que tenía el doctor Madinaveitia, suegro de Castro, en El Ventorrillo, cerca de las primeras instalaciones serranas del Club Alpino Español. Al hilo de ese recuerdo, habla Reyes del importante papel que habían jugado Francisco Giner y sus colaboradores de la Institución Libre de Enseñanza en el descubrimiento de aquel paisaje montañoso y en el fomento de las excursiones, allí y en muchos otros lugares. Habían inaugurado en España «la tradición del amor a la naturaleza», y con ella se había desarrollado también, gracias a ellos, el «culto al Guadarrama», que contaba en los años veinte, cuando escribe Reyes su recuerdo, con «sacerdotes» como Ramón Menéndez Pidal o Enrique de Mesa. Y todo ello procedía en último término de la nueva actitud hacia la naturaleza y el paisaje que Giner había iniciado y promovido, desde los años ochenta del siglo anterior. «Supongo —escribe Reyes-que fue Francisco Giner de los Ríos el inventor del Guadarrama» (Reyes, 1956: 393).

Y no solo del Guadarrama. Puede decirse también, en términos generales, que Giner fue el inventor del paisaje de España, en la medida en que fue precisamente él quien introdujo y promovió un nuevo modo de verlo y valorarlo, abriendo así el camino de su descubrimiento moderno. Fue el hallazgo de algo nuevo, ignorado hasta entonces. Porque el paisaje, tal y como se entiende en el horizonte de la modernidad, no es solo materialidad, objetividad visible, sino también, al tiempo, elaboración cultural, imagen subjetiva apoyada en ideas y sentimientos. Para hacerse paisaje, lo visible necesita el concurso de la mirada, que juega, como ha señalado Jean-Marc Besse, un «papel constituyente» (Besse, 2010: 121). Y eso fue lo que aportó Giner por vez primera en España: la mirada de la modernidad paisajística, capaz de elevar lo visible a la categoría de paisaje. Esta fue la clave de su invención de la Sierra de Guadarrama y, yendo más allá, del paisaje de España. Veamos cómo se concretó y desenvolvió esa perspectiva paisajística de Francisco Giner ${ }^{1}$.

1. Las páginas que siguen se apoyan en buena medida en algunos trabajos anteriores del autor sobre el mismo asunto, entre los que se cuentan principalmente Ortega Cantero, 2001; 2007a; 2012. 


\section{La perspectiva del paisajismo geográfico moderno}

La mayor parte de la amplia labor de Francisco Giner se llevó a cabo en el marco de la Institución Libre de Enseñanza, fundada en Madrid en 1876, en la que tuvo durante cuarenta años, hasta su muerte en 1915, el principal protagonismo, y con la que mantuvo siempre una profunda identificación. La Institución fue, en palabras de Rafael Altamira, «su creación más honda y su medio de influencia más poderoso» (Altamira, 1915: 61), y en su Boletín ofreció, como advirtió Juan López-Morillas, «sus ideas y esperanzas, sus recelos y aversiones», hasta hacer de él «una especie de diario íntimo» (López-Morillas, 1988: 30). La actividad de Giner —y la de la Institución - tuvo una finalidad principal: modernizar el panorama educativo, científico y cultural de España, o, dicho en otros términos, europeizarlo. Se trataba de incorporar los fundamentos de la cultura europea —su «sustancia», como precisó López-Morillas, no sus «accidentes» o sus «formas aisladas» (López-Morillas, 1980: 29-30)_, y de aplicar sus posibilidades a la modernización de la situación española. Y todo ello sin renunciar a lo español, a los valores de variada índole del propio horizonte cultural. Había en la Institución Libre de Enseñanza, como señaló Azorín, «una nota de universalidad y otra nota de españolismo», y ambas notas se hallaban igualmente presentes en el pensamiento de su principal impulsor: "Giner y su europeísmo, aliado al amor por el paisaje de Castilla. Giner, europeo y apasionado del Guadarrama» (Azorín, 1967: 124, 127).

Ese empeño de modernización fue uno de los rasgos característicos de los planteamientos de Francisco Giner y de la Institución Libre de Enseñanza. A ello se refirió el propio Giner, entonces Rector, en su discurso inaugural del curso académico 1880-81. La Institución se había orientado, dijo, «en los progresos obtenidos por otras naciones», y había enviado a sus profesores "para estudiarlos de cerca», procurando después aplicar esos progresos a la situación española, adaptándolos a su «genio y circunstancias» y completándolos con los resultados de la propia experiencia. Esa era precisamente la clave para «iniciar algún nuevo camino», acorde con los planteamientos actualizados de la cultura pedagógica de entonces (Giner de los Ríos, 2004a: 267). Y con ese afán de modernización, de introducir en España, procurando adaptarlos y completarlos, los progresos obtenidos por otras naciones, se relaciona la visión del paisaje ofrecida inicialmente por Francisco Giner y prolongada después, siguiendo sus pasos, por la Institución Libre de Enseñanza. 
Entre los progresos foráneos de índole intelectual y educativa que interesaron a Giner y a la Institución, se contó la perspectiva de la geografía moderna, inicialmente promovida, desde principios del siglo XIX, por Alexander von Humboldt y Karl Ritter, y, dentro de ella, el nuevo modo de entender el paisaje principalmente debido al primero de ellos. El paisajismo geográfico moderno, conformado primeramente por Humboldt y continuado después en la geografía decimonónica posterior, fue así unos de esos progresos obtenidos por otras naciones que Francisco Giner y la Institución Libre de Enseñanza incorporaron y aplicaron a sus consideraciones sobre el paisaje español. Conocieron y aplicaron, por tanto, las actitudes y las intenciones que caracterizaron los planteamientos paisajísticos de la geografía moderna, su manera de acercarse a lo que el paisaje es y a lo que significa, y su interés en aunar en el empeño puntos de vista distintos pero complementarios, en términos físicos y también intelectuales, apoyándose siempre en lo que Vincent Berdoulay y Hélène Saule-Sorbé denominaron «la movilidad de la mirada» (Berdoulay \& Saule-Sorbé, 1998). La visión del paisaje español conformada por Giner y secundada por la Institución recoge todos esos ingredientes, y se inscribe de forma plena en las coordenadas de la modernidad paisajística europea de su tiempo. Se introdujo así en España el componente geográfico (y paisajístico) de la cultura europea moderna, es decir, la cultura geográfica y, dentro de ella, la cultura geográfica del paisaje, vinculadas a la modernidad cultural europea.

Ese paisajismo de cuño geográfico, conformado en el marco del horizonte romántico, compartía con otras modalidades coetáneas de similar finalidad — desde las predominantemente artísticas, al modo de Rousseau, Saint-Pierre, Friedrich o Turner, hasta las más vinculadas a intenciones científicas y naturalistas, como las de Saussure o Ramond- las claves de la nueva manera de entender el paisaje, de verlo y de valorarlo, pero aportaba también algunas peculiaridades. Una de ellas, sin duda la más interesante y fecunda, fue la búsqueda de una relación equilibrada entre las miradas explicativa y comprensiva —entre la ciencia y el arte, si se prefiere, o entre la razón y el sentimiento- a la hora de entender el paisaje. El paisajismo geográfico alentado por Humboldt tuvo en cuenta al tiempo el modo de ver y valorar el paisaje de los naturalistas, a la manera de Saussure, con su énfasis explicativo, científico, y el de los artistas, más dados a lo comprensivo y estético, como había mostrado ejemplarmente Rousseau. Unos y otros habían sido ya conscientes, desde luego, de la necesidad de compaginar la explicación y la comprensión, los puntos de vista de la ciencia y el arte, a la hora de entender el paisaje, pero en ambos 
casos la importancia concedida a esos dos componentes se inclinaba decididamente hacia uno de ellos, el explicativo o el comprensivo, dejando al otro en un lugar secundario. La singularidad de la propuesta paisajística de Humboldt, apoyada en su amplitud de miras y en su sólida formación naturalista y humanista al tiempo, fue conformar una visión en la que la explicación y la comprensión igualaban su importancia.

El propio Humboldt señaló con claridad su intención de aunar equilibradamente ambas miradas en sus Cuadros de la Naturaleza, el libro que abrió, en 1808, el camino de ese nuevo paisajismo geográfico. Quería hablar a la razón y al sentimiento de sus lectores, hermanar la historia natural y la estética, «cautivar la imaginación y enriquecer la vida con ideas y conocimientos nuevos» (Humboldt, 1990, I: 5). El editor de la traducción francesa de ese libro llamó la atención en una nota sobre la original convergencia en sus páginas de la explicación científica y la comprensión artística: era, decía, una obra maestra, capaz de ofrecer la suma de la perspectiva de Bernardin de Saint-Pierre y la exactitud de la ciencia. Humboldt era un científico destacado y, además, un buen escritor, dotado de sensibilidad literaria y de una notable capacidad expresiva, y ambas cualidades hicieron posible su modo de entender el paisaje y de representarlo, aunando la mirada explicativa y la comprensiva. Y este rasgo característico del paisajismo geográfico de Humboldt, que se prolongó después en los exponentes más destacados del paisajismo geográfico, ayudó a ampliar su influencia posterior: no solo se dejó sentir en el mundo de la ciencia, en el mundo más interesado por describir y explicar el paisaje, sino también en el ámbito del arte, entre los autores más preocupados por sentirlo y comprenderlo. El paisajismo de Humboldt tuvo así una influencia directa y notable en la cultura europea decimonónica, en sus manifestaciones científicas y en sus expresiones artísticas, pictóricas y literarias.

En ese panorama general de influencia se enmarca la que tuvo la perspectiva paisajística de Humboldt en Francisco Giner y, en buena medida a través de él, en la Institución Libre de Enseñanza. Bernardo Giner, hermano del anterior, tradujo entre 1874 y 1878, años cercanos a la fundación de la Institución, tres obras paisajísticamente fundamentales de Humboldt: Cuadros de la Naturaleza, Sitios de las cordilleras y monumentos de los pueblos indígenas de América, y Cosmos: ensayo de una descripción física del mundo. Y a la influencia directa de Humboldt se añadió la del geógrafo francés Élisée Reclus, que prolongó la perspectiva paisajística del primero y la aplicó, en el tomo primero de su Nouvelle Géographie Universelle, publicado en 1876, el año del nacimiento de la Institución, al 
paisaje de España. La influencia de la obra de Reclus, con sus imágenes del paisaje español y, en especial, del paisaje castellano, contribuyó a reforzar la presencia del paisajismo geográfico moderno en el círculo gineriano e institucionista.

Esa fue la perspectiva paisajística de signo geográfico que incorporaron Giner y la Institución Libre de Enseñanza. Con ella pudieron superar los límites estéticos de las anteriores imágenes románticas del paisaje de España y proponer un modo de entenderlo más amplio y complejo, simultáneamente interesado en su explicación y en su comprensión. Y esta nueva visión del paisaje español promovida por Giner y la Institución estuvo estrechamente relacionada con su ideario y sus aspiraciones, con su forma de entender la situación del país, de valorar su pasado y su presente, y de imaginar las soluciones que consideraban más adecuadas para sus problemas. Las cualidades que Francisco Giner y los institucionistas descubren en el paisaje, los valores y los significados que le atribuyen, son inseparables de su pensamiento y de sus creencias. La imagen del paisaje forma parte de su «imaginario», del conjunto de representaciones que expresan simbólicamente la concepción del mundo que les rodea y las posibilidades de mejorarlo. De ahí que hubiese una clara conexión entre su visión del paisaje de España y su orientación patriótica, con su interés por definir las claves de la identidad nacional, los rasgos distintivos del carácter y de la historia del pueblo español. Porque, como señaló Inman Fox, Giner y la Institución participaron activamente en «la construcción de una identidad nacional española» (Fox, 1997: 15), y su modo de entender el paisaje estuvo estrechamente relacionado con los diagnósticos y las aspiraciones de ese horizonte. Para Giner y para la Institución, acercarse al paisaje era un modo de acercarse al pueblo español, a su carácter y a su historia. Esa conexión no hacía sino traducir la convicción del paisajismo geográfico moderno sobre la existencia de correspondencias entre los paisajes y los pueblos que los habitan. Por eso desempeñó el paisaje un papel destacado en el horizonte intelectual y político del círculo gineriano e institucionista: su modo de verlo y valorarlo comprendía una clara intención de afirmación nacional, de búsqueda de las notas distintivas, propias, de la identidad nacional española.

\section{Los valores del paisaje}

Francisco Giner resumió su perspectiva paisajística en el artículo que, con el título de «Paisaje», publicó en 1886 en La Ilustración Artística, en el que puede distinguirse con bastante claridad la presencia del horizonte 
geográfico moderno. La cercanía de Giner a ese horizonte pudo verse favorecida, en primer lugar, por su conocimiento de la obra de Humboldt, al que cita en ese artículo, y, en segundo lugar, por la común ascendencia, idealista y alemana, del pensamiento geográfico y del gineriano, que hizo que ambos mostrasen coincidencias significativas a la hora de entender y valorar el mundo exterior, la naturaleza y el paisaje, y que las propuestas paisajísticas del primero pudiesen integrarse fácilmente en los planteamientos del segundo. La idea de paisaje manejada por Giner es un ejemplo expresivo de esa cercanía. Al igual que la geografía moderna, Francisco Giner concibe el paisaje como la expresión visible de un orden natural —un paisaje natural - en el que queda comprendido el hombre. Lo entiende por tanto como una entidad natural, de la que forman parte diversos elementos, «tantos como fuerzas, seres y productos despliega la naturaleza ante nuestros ojos», desde «la tierra y el agua en sus formas» $\mathrm{y}$ «el mundo vegetal con sus tipos, figuras y colores», hasta «el hombre con sus obras» (Giner de los Ríos, 2004d: 792). Y entre estos elementos, el relieve juega, como lo jugaba en el paisajismo geográfico coetáneo, un papel de especial relevancia en la caracterización del paisaje, incluyendo sus cualidades estéticas. Hay una estrecha relación, dice Giner, entre el suelo y el paisaje, entre la geología y la estética, y esa relación depende de la naturaleza litológica, de la disposición tectónica y del comportamiento frente a la erosión química superficial de los materiales. Sus comentarios sobre este asunto son una muestra sumamente elocuente de la vertiente geográfica de su perspectiva paisajística, como puede comprobarse en párrafos como el que sigue:

Esta relación del suelo con el paisaje, de la geología con la estética, que ya ilustraron en sus tiempos un Cuvier y un Humboldt, presenta problemas de interés extraordinario. Respecto de los materiales de los terrenos arcaicos, v. g., pueden observarse delicadas diferencias entre las formas graníticas y las gnéisicas, diferencias tan visibles casi como las que separan ambas clases de formas de las que ofrecen los conglomerados de Montserrat, o las calizas carboníferas en las cumbres de los Picos de Europa, o los depósitos lacustres de los llanos de la Tierra de Campos. Sin embargo, la distinta posición orográfica de unos mismos materiales, esto es, el plegamiento de las capas, influye considerablemente en el paisaje. Igualmente, una acción química superficial puede dar a las rocas un aspecto muy diverso del que usualmente revisten. Recuerdo el magnífico tono frío amoratado de los acantilados del circo de las Dos Hermanas, en el macizo de Peñalara, debido a la hidratación del óxido de hierro contenido en las micas de sus gneises; mientras que en el puerto del Reventón, 
en el vallecito de la Berzosa (debajo de la Maliciosa y de las Cabezas de Hierro), y en tantas y tantas otras partes, ese mismo gneis, por cuyas lajas corre una fina capa de agua, ofrece los rojos más cálidos, ricos y transparentes, merced a otro grado de hidratación de esos mismos hierros (Giner de los Ríos, 2004d: 796-797).

Los elementos del paisaje - el relieve, la vegetación, el agua, el cielo, la atmósfera, los animales, el hombre y sus obras - forman una unidad natural, resultado de un conjunto de relaciones naturales, de la que el hombre es un componente natural más, que, al igual que los restantes, pertenece al orden de la naturaleza. El hombre y sus obras forman parte del paisaje, advierte Giner, «a condición de avenirse a no representar más que uno de tantos accidentes, de subordinarse a la naturaleza - por decirlo asídeshabitada». De esa forma, acatando el orden natural y las relaciones que comprende, es como pasan a formar parte del paisaje las obras debidas al hombre - casas, caminos, tierras cultivadas - y «el hombre mismo, cuya presencia anima con una nueva nota de interés el cuadro entero de la naturaleza». El paisaje expresa así el orden natural, el resultado unitario, sintético, de las relaciones naturales entre todos sus componentes, físicos y humanos. El paisaje es la expresión visible de una unidad geográfica natural. «En su más rigurosa acepción —añade Giner-, el paisaje es la perspectiva de una comarca natural; como la pintura de paisaje es la representación de esa perspectiva» (Giner de los Ríos, 2004d: 792-793).

Esta visión naturalista del paisaje, similar a la que suscribió la geografía a lo largo del siglo XIX, entraña algunos aspectos sin duda importantes. Supone que el hombre es parte de la naturaleza, que mantiene con ella una relación continua que queda plasmada en el paisaje. Hay, según Giner, una clara «relación entre la constitución geológica, el relieve del suelo, el clima, el medio natural, en suma, y el hombre», y esa relación deja su huella «en la constitución de nuestro cuerpo como en la de nuestra misma fantasía, de donde trasciende a nuestros gustos, hábitos, artes, a la obra y modo entero de la vida» (Giner de los Ríos, 2004d: 797). El paisaje expresa la conexión entre el hombre y su ambiente natural, y entender el paisaje es, en consecuencia, entender los rasgos característicos que ambos comparten. Podemos descubrir en el paisaje las cualidades principales de su caracterización natural, y tales cualidades serán también atribuibles a los hombres que allí habitan. Hay hondas correspondencias entre la naturaleza y el modo de ser, de pensar y de sentir de los hombres relacionados con ella, y de todo ello da cumplida cuenta el paisaje. El acercamiento al 
paisaje es un modo de acercarse al conocimiento del orden natural del mundo y del lugar que el hombre ocupa en él.

El paisaje se entiende además como una realidad dotada de sentido, con valores, cualidades y significados, que hay que tener en cuenta para captarlo cabalmente. Por eso el acercamiento al paisaje requiere, como advirtió Humboldt, aunar la explicación y la comprensión, simultanear el conocimiento apoyado en la razón y el pensamiento con el que se apoya en el sentimiento y la imaginación. Son dos vías de conocimiento distintas y complementarias, y ambas son necesarias para llegar a entender la verdadera entidad del paisaje, a explicar sus formas y a comprender su sentido. De ahí que la visión de Giner no solo atienda a la descripción e interpretación de los rasgos fisonómicos del paisaje, sino que se adentre en la comprensión de su sentido, procurando valorar sus significados subyacentes, su dimensión cualitativa. Y todo ello contribuye a agrandar el interés del paisaje. Entenderlo es también abrirse a un mundo de significados, de valores y cualidades, cuya comprensión puede ayudar sustancialmente a mejorar la educación del hombre. El contacto con el paisaje se convierte así en un medio educativo de primer orden: permite educar no solo la inteligencia, sino además, al tiempo, la sensibilidad y la imaginación; ayuda a cultivar simultáneamente, sin disociaciones inconvenientes, las capacidades intelectuales, éticas y estéticas de la persona. El «contacto purificador de la Naturaleza» favorece siempre, en palabras de Giner, «la expansión de la fantasía, el ennoblecimiento de las emociones, la dilatación del horizonte intelectual, la dignidad de nuestros gustos y el amor a las cosas morales» (Giner de los Ríos, 2004d: 799).

El contacto directo con el paisaje puede ser una experiencia gozosa. A través de él, el hombre puede compenetrarse con el orden natural, establecer conexiones profundas — «analogías misteriosas y morales armonías», en palabras de Humboldt (1874-1875, II: 4)— con lo que le rodea, y captar la entidad y el alcance de las correspondencias entre lo exterior y lo interior que la visión moderna del paisaje considera fundamentales. Humboldt habló también de estas correspondencias, de los «lazos secretos e indisolubles» que unen lo de fuera y lo de dentro, de cómo «el mundo físico se refleja en lo más íntimo de nuestro ser con toda su verdad viviente», para concluir que es justamente en esa relación, en esa «armonía», en la que "descansan los más nobles goces que la naturaleza nos ofrece» (Humboldt, 1876: 210). De esos nobles goces, asociados a las correspondencias entre lo exterior y lo interior que se dejan sentir en la relación directa con el paisaje, habla Giner de forma elocuente, evocando, 
con aliento pictórico, la impresión que había sentido durante un anochecer en la Sierra de Guadarrama:

Jamás podré olvidar una puesta de sol, que, allá en el último otoño, vi con mis compañeros y alumnos de la Institución Libre desde estos cerros de las Guarramillas. Castilla la Nueva nos aparecía de color de rosa; el sol, de púrpura, detrás de Siete Picos, cuya masa, fundida por igual con la de los cerros de Riofrío en el más puro tono violeta, bajo una delicada veladura blanquecina, dejaba en sombra el valle de Segovia, enteramente plano, oscuro, amoratado, como si todavía lo bañase el lago que lo cubriera en época lejana. No recuerdo haber sentido nunca una impresión de recogimiento más profunda, más grande, más solemne, más verdaderamente religiosa (Giner de los Ríos, 2004d: 799).

En la existencia de conexiones y correspondencias entre el paisaje y quienes lo habitan, reconocidas expresamente por el paisajismo geográfico y por Giner, se apoya la importancia adquirida por el conocimiento del primero a la hora de descubrir los rasgos característicos de los segundos. La solidaridad entre el hombre y el paisaje se manifiesta a la vez de forma individual y colectiva. Conocer el paisaje es un medio para conocer a los hombres relacionados con él. Francisco Giner habla, por ejemplo, del «grave, seco, y un tanto bravío habitante de la no menos grave, seca y bravía tierra de Campos» (Giner de los Ríos, 2004e: 786). Y junto a su expresión individual, esos nexos muestran también una dimensión colectiva o social. Las características propias de los grupos sociales - de los pueblos- están asociadas a las de los paisajes en los que viven y se desenvuelven, y por eso estos adquieren significado histórico e identitario. El conocimiento del paisaje ayuda así a identificar las claves del propio pasado histórico y de la identidad común conformada a lo largo de ese pasado. En el horizonte historiográfico gineriano e institucionista, deudor de las ideas de Herder y Krause, interesado siempre en descubrir, bajo la superficie de la historia externa u oficial, la historia interna o intrahistoria del pueblo español, la que se identifica con su carácter o psicología, con su cultura colectiva, la consideración del paisaje adquiere una notable importancia. Al igual que ocurre con el arte o la literatura, el paisaje nos acerca a la caracterización intrahistórica del pueblo español, a los rasgos más genuinos de su tradición cultural y de su identidad colectiva. En este marco interpretativo se sitúan los elocuentes comentarios de Rafael Altamira sobre el sentido y el alcance del paisajismo de Giner, de quien dice que supo sentir el paisaje castellano «con una emoción tan honda y una tan grande claridad de concepto, que le llevaron hasta la más profunda 
raíz de patriotismo que emana de la tierra en que formó un pueblo su alma y su historia» (Altamira, 1921: 220).

La aportación paisajística de Francisco Giner fue valiosa y fecunda. Su modo de entender el paisaje, de verlo y valorarlo, que incorporó la perspectiva del paisajismo geográfico moderno, fue tan innovador como feraz. Abrió el camino de la cultura moderna del paisaje en España, e influyó de manera muy notable no solo en todo el paisajismo promovido, hasta su desaparición en 1936, por la Institución Libre de Enseñanza, que secundó fielmente sus ideas y sugerencias, sino también, al tiempo, en otros círculos intelectuales, artísticos y deportivos interesados por el paisaje. Es lo que sucedió, por ejemplo, con los escritores y pintores de la denominada generación del 98 (Martínez de Pisón, 2012; Ortega Cantero, 2007b), o con los enfoques de la política turística dirigida por el marqués de la VegaInclán (Ortega Cantero, 2014b), o, en fin, con el planteamiento cultural y excursionista de las primeras sociedades de alpinismo madrileñas (Ortega Cantero, 2014a). Giner contribuyó así notablemente a que arraigaran y se extendiesen en España las claves de la visión moderna del paisaje. Su modo de entenderlo, de pensarlo y de sentirlo, quedó ejemplarmente plasmado en su artículo de 1886 y en las diversas evocaciones de paisajes españoles que aparecieron en algunos de sus restantes escritos.

\section{Imágenes del paisaje español}

Francisco Giner ofreció diversas imágenes del paisaje español, generalmente asociadas a sus relatos de excursiones. En el dedicado a «Santiago de Peñalba», por ejemplo, de 1884, habló del paisaje «de primer orden» en el que se inscribe la iglesia, característico del Bierzo: «valles risueños y estrechísimos, montañas de rápida pendiente, copioso arbolado, y una abundancia de cascadas y arroyos sin igual en otras comarcas semejantes de Asturias, Santander y Galicia, y que mantiene en la vegetación indescriptible frescura» (Giner de los Ríos, 2004e: 788). Y entre sus impresiones paisajísticas más acabadas, se cuentan las incluidas en sus escritos sobre «Mérida y Badajoz», de 1879, y sobre «El Real Sitio del Pardo», de 1883 , y, por supuesto, en el titulado «Paisaje», ya citado, de $1886^{2}$. En el primero, habla Giner de las ruinas de los acueductos romanos de

2. Tanto el escrito sobre «Santiago de Pañalba», como los dedicados a «Mérida y Badajoz» y a «El Real Sitio del Pardo», se recogieron en el tomo vigésimo de las obras completas de Francisco Giner, aparecido en 1936, con el título de Arqueología artística de la Península y una nota preliminar de Juan Uña y Sarthou. Los tres, junto al titulado «Paisaje», que no se recogió en esas obras completas, han sido incluidos después en el apartado 
Mérida, grandiosas y pintorescas a la vez, que se funden con otros elementos naturales y humanos - la llanura, el río, la vegetación, la luz, el cielo, las cigüeñas, el ferrocarril- para formar conjuntamente un paisaje de "gravedad serena y melancólica», capaz de producir una honda impresión. Nada mejor para comprobar esas cualidades que contemplarlo, como hace Giner, desde el puente romano del arroyo Albarregas:

Desde este punto de vista pintoresco, nada excede a la impresión de los gigantescos pilares que se contemplan desde el puente de Albarregas (Alba regia), romano también, pero completamente modernizado: aquellas masas imponentes, apenas enlazadas por las mal unidas dovelas de alguno que otro tramo; aquel tono tan grave, tan riguroso y caliente; aquella llanura suavemente ondulada, como la campiña de Roma; aquel verdor que brota en los cimientos y pugna por elevarse hasta las más altas piedras, sobre las cuales se apiñan las cigüeñas en inmenso número; aquel ferrocarril tendido por bajo de los arcos, y aquel río, y aquella luz, y aquel cielo, forman uno de esos paisajes que excitan un mundo de ideas, de sentimientos, de representaciones en la fantasía (Giner de los Ríos, 2004c: 749-750).

El Pardo fue uno de los lugares más visitados por Giner y sus compañeros institucionistas. Fueron proverbiales sus paseos dominicales, desde la sede de la Institución Libre de Enseñanza, en el Paseo del Obelisco (el actual Paseo del General Martínez Campos) desde mediados de los años ochenta, hasta la Puerta de Hierro y El Pardo. Acompañaban a Giner sus amigos y colaboradores de la Institución, y cuenta Constancio Bernaldo de Quirós que algunos de los que residían fuera procuraban aprovechar sus estancias en Madrid para participar en esos paseos y tener así ocasión de hablar con él tranquilamente (Bernaldo de Quirós, 1964: 175-179). «De recién llegado a Madrid —decía Juan Ramón Jiménez-, todos los domingos iba yo al Pardo y regresaba a pie, acompañando a D. Francisco Giner» (en Reyes, 1956: 393). Al norte y al lado de la ciudad de Madrid, unido a ella por una carretera pequeña y agradable — con «las más hermosas perspectivas en todo su trayecto», en palabras del propio Giner (2004b: 761)—, El Pardo ofrecía a los institucionistas no solo el atractivo de su paisaje natural, con el valioso encinar que lo caracterizaba, y de su palacio renacentista, sino también el interés añadido de constituir un sitio privilegiado para contemplar el panorama de la Sierra de Guadarrama. Acercarse al Pardo era

«Sobre arte, literatura y paisaje» de sus Obras selectas (Giner de los Ríos, 2004b; 2004c; 2004d; 2004e). 
también, al tiempo, acercarse a una visión amplia, panorámica, de la Sierra de Guadarrama. Giner trazó una imagen muy expresiva de las cualidades paisajísticas del Real Sitio del Pardo:

Este hermosísimo parque, último resto casi, con la Viñuela, la Escorzonera de Remisa, el monte de Boadilla y algún otro manchón insignificante, de la espléndida selva que un tiempo rodeaba a Madrid y que el atraso, la preocupación y la ignorancia han ido talando y reduciendo hasta dejarla trasformada en pobrísima tierra de pan llevar, ofrece todavía, gracias a haberse librado de las imprudencias de la desamortización, un admirable paisaje, donde el sombrío verdor de las encinas, la esmeralda de los pinos, la plateada seda de las retamas, las zarzas, jaras, rosales, espinos, sauces, fresnos, chopos y álamos blancos, cuyo pie alfombran con inagotable profusión el tomillo, el cantueso, el romero, la mejorana y otras olorosas labiadas, que huellan sin cesar gamos y conejos, forman una vista grandiosa, coronada por la vecina sierra con su cresta de nieve en el invierno, sus radiantes celajes en el verano, y en todo tiempo con su imponente masa y graves tintas (Giner de los Ríos, 2004b: 760-761).

Del paisaje de Castilla habló Giner en diferentes ocasiones, y su modo de verlo y valorarlo renovó decisivamente su imagen, distanciándola de la que habían generalizado antes, casi siempre en términos despectivos, los autores románticos. Fue esta una aportación paisajística muy innovadora e influyente. «Giner —advirtió López-Morillas — se adelanta en muchos años a los hombres del 98 en lo que es, también a su modo, un "descubrimiento" suyo: el paisaje castellano, de cuyo aprecio y enaltecimiento tantos testimonios dejó» (López-Morillas, 1988: 103). A propósito de Paredes de Nava, lugar de nacimiento del escultor Berruguete, «en el corazón de lo más castellano de Castilla», habló Giner, por ejemplo, de «esa Castilla la Vieja, tan grave, tan adusta, tan entristecida, tan pálida, cuyo paisaje, como ha dicho un pensador original, está en el cielo, es decir, en las pompas de su azul profundo hasta la negrura y de sus incomparables celajes» (Giner de los Ríos, 1936: 65). En su mencionado artículo de 1886, habló también del paisaje castellano, distinguiendo sus dos modalidades madrileñas - montaña y llano - y trazando una imagen moderna, profundamente innovadora, de la Sierra de Guadarrama, atenta a sus valores naturales, históricos y culturales, que acuñó un modelo posteriormente muy influyente. La revista Peñalara estableció un cierto paralelismo entre Rousseau, que fue para todo el ámbito europeo «el descubridor de la belleza alpina», y Giner, que «fue para nosotros el revelador del Guadarrama» (Peñalara, 1915: 33). Y Eduardo Martínez de Pisón incluyó la visión de la Sierra de 
Guadarrama ofrecida por Giner y por la Institución Libre de Enseñanza entre las que contribuyeron de manera más destacada a conformar el significado cultural, incluso simbólico, de algunas montañas europeas. El valor cultural que adquiere el Guadarrama en el horizonte de Giner y la Institución es comparable, como advierte Martínez de Pisón, al que logran otras montañas europeas "por el estudio y el esfuerzo realizado en ellas por un ilustrado o un científico: así el Mont Blanc con De Saussure, el Monte Perdido con Ramond o el Teide con Humboldt, en el paso del siglo XVIII al XIX» (Martínez de Pisón, 1983: 139).

\section{El paisaje de la Sierra de Guadarrama}

La imagen de la Sierra de Guadarrama ofrecida por Francisco Giner fue la mejor expresión de su modo de entender el paisaje. Y a través de ella, teniendo en cuenta sus fundamentos y sus características, es posible distinguir con bastante claridad las claves de ese modo de verlo y valorarlo. Lo primero que conviene señalar, en este sentido, es que, en consonancia con las directrices del paisajismo geográfico moderno, la visión de la Sierra de Guadarrama de Giner estuvo estrechamente relacionada con las nuevas interpretaciones de ese ámbito montañoso - y de la Meseta a la que, como parte de la Cordillera Central, pertenecía- elaboradas por los geólogos de su tiempo. José Macpherson, que fue profesor de «Trabajos geológicos» de la Institución Libre de Enseñanza y dirigió la «Sociedad para el estudio del Guadarrama» creada en su seno a finales de 1886, desempeñó un papel destacado en todo ello. Mantuvo una gran amistad con Giner - que le consideraba «el primero de nuestros geólogos en su tiempo» (Giner de los Ríos, 1922: 13)—, a quien inició en el conocimiento naturalista de la Sierra de Guadarrama, aportándole, dice Bernaldo de Quirós, la educación que necesitaba para «comprender la grandiosa tectónica de la tierra» (Bernaldo de Quirós, 1922: 186). Las investigaciones de Macpherson renovaron la concepción de la organización geológica de la Península Ibérica, y ofrecieron una nueva interpretación del importante papel desempeñado en ella por la Cordillera Central en general y la Sierra de Guadarrama en particular. A esta última, y en especial al ámbito del macizo de Peñalara y del valle del Lozoya, le atribuyó Macpherson una singular importancia: formaba parte de la Cordillera Central, la «verdadera columna vertebral de la Península Ibérica» (Macpherson, 1883: 358), y era además el sector más antiguo y más resistente de esa alineación montañosa, perteneciente toda ella al núcleo originario del conjunto geológico peninsular. 
El significado atribuido por Macpherson a la Cordillera Central y, dentro de ella, a la Sierra de Guadarrama estaba relacionado con el que se concedió entonces a la Meseta, expuesto con claridad por Salvador Calderón, que fue también profesor de la Institución. La Meseta central o castellana era, según Calderón, el núcleo originario de la Península, la parte medular de lo que el autor denominó, con criterio naturalista, «la primitiva España», que había presidido la historia geológica peninsular: «La Meseta central es el gran factor de toda la constitución geológica, estructura y orografía de la Península, desde la cuenca del Ebro y límites españoles de las estribaciones pirenaicas, hasta las playas meridionales». Adquirió así la Meseta, en la interpretación actualizada de la organización geológica peninsular que se impuso en los últimos decenios del siglo XIX, una importancia natural sobresaliente. Recordando lo que había dicho, a mediados de los años setenta, el autor de la Nouvelle Géographie Universelle, Calderón afirmó que la Meseta castellana «es la Península en pequeño con todos los rasgos fundamentales de su forma, pudiendo decirse geológicamente de ella, como en sentido geográfico y político lo ha dicho Reclus, que es la España por excelencia» (Calderón y Arana, 1885: 136, 169-170).

Ambas valoraciones naturalistas, geológicas, de la Meseta central o castellana y de la Sierra de Guadarrama no fueron ajenas a las valoraciones culturales que Giner y sus compañeros de la Institución Libre de Enseñanza ofrecieron de esos mismos ámbitos. Hay evidentes correspondencias - congruentes con los planteamientos del paisajismo geográfico moderno- entre las nuevas valoraciones naturalistas de la Meseta central o castellana y de la Sierra de Guadarrama, con la importancia que les atribuyen en la historia geológica peninsular, y las también nuevas valoraciones culturales que de esos mismos ámbitos - Castilla y el Guadarramaproponen Giner y sus colaboradores de la Institución, con la importancia que les atribuyen en relación con la historia de España y la conformación, a lo largo de esa historia, de la identidad nacional. La elevada significación cultural que Francisco Giner y la Institución Libre de Enseñanza concedieron a Castilla y, dentro de ella, a la Sierra de Guadarrama estaba directamente conectada con la importante significación natural que las interpretaciones geológicas modernas atribuyeron a esos mismos ámbitos geográficos.

Giner ofreció en su artículo de 1886 una imagen del paisaje de la Sierra de Guadarrama en la que convergían la explicación y la comprensión. La explicación del paisaje era de índole naturalista, y procuraba dar cuenta 
de los componentes y relaciones naturales que lo organizaban, mientras que su comprensión era de signo cultural, e intentaba captar y valorar sus cualidades y significados. En relación con lo primero, con la vertiente explicativa, Giner señala algunos lugares del Guadarrama especialmente impresionantes por su situación y su caracterización natural. Es el caso de «las Cabezas de Hierro, y los espléndidos valles que dominan», o de «la magnífica y vecina Peñalara, con sus ventisqueros, sus lagunas, sus circos, sus acantilados, sus panoramas espléndidos, que abrazan desde el Pisuerga al Manzanares» (Giner de los Ríos, 2004d: 800). Y en sus descripciones panorámicas, de esos panoramas a menudo espléndidos que permiten abarcar las alturas del Guadarrama, se deja sentir el aliento naturalista y geográfico del modo gineriano de ver el paisaje. Procura en ellas prestar atención al tiempo a los elementos principales del paisaje y a las formas de organización natural que resultan de las relaciones entre ellos. Como en el horizonte geográfico moderno, la visión panorámica es en Giner un modo de acercarse a la organización del paisaje, al orden natural que lo fundamenta. Tal es el caso, por ejemplo, de la descripción panorámica que ofrece desde la cumbre de las Guarramillas, después de haber recorrido el camino entre la estación del ferrocarril de Villalba y el puerto de Navacerrada:

Dejamos muy atrás la zona de la vid; estamos en plena región alpestre. Sigamos, y llegaremos a la cumbre, al puerto de Navacerrada, límite de las dos Castillas, cuyo desnivel se advierte al punto, y divisoria entre el Tajo y el Duero; y si tomamos por la ladera hacia el Este, con solo subir unos cien metros, al primer cerro de las Guarramillas, contemplaremos el más grandioso panorama. Tenemos debajo las apretadas masas de los pinares de Valsaín, al fin de cuyos tonos, oscuros y enérgicos, clarean con espléndida luz los llanos de Segovia, que muestra allá en la bruma las torres de sus monumentos; coronándolo todo el imponente macizo de Peñalara, al E. del cual se extiende el suave cordón, que forma el puerto del Paular y defiende el valle del Lozoya; mientras que al Sur, la meseta de Castilla la Nueva, en que Madrid dibuja apenas su silueta cárdena, prolonga las curvas de su modelado hasta perderse en el celaje; y al O., la cadena de la cordillera viene corriendo por cima del Escorial a cerrar del otro lado el puerto con las quebradas alturas de Siete Picos. Desde este núcleo, multitud de ríos se van formando y despeñando en distintas direcciones: por la vertiente meridional, el Guadarrama, el Manzanares, el Guadalix, el Lozoya, el Jarama, que más o menos pronto llevan sus aguas hasta el Tajo; por la vertiente norte, el Eresma, el Valsaín, el Clamores, el arroyo de Moros, que van a acabar en el Duero (Giner de los Ríos, 2004d: 798-799). 
Ofrece Giner también algunos comentarios que no se limitan al ámbito del Guadarrama, sino que se refieren al conjunto del paisaje de la provincia de Madrid, relacionando, con sus similitudes y diferencias, el paisaje montañoso de la Sierra y el de la cuenca sedimentaria. A semejanza de lo que estaban planteando Macpherson y Calderón en términos geológicos, la valoración que Giner propone de la Sierra de Guadarrama se inscribe en la que, con carácter más general, plantea a propósito de Castilla. Montaña y llano se asocian en la perspectiva de Giner, y ambas formas, aunque distintas, comparten características y valores que remiten, en último término, a su común pertenencia al núcleo de la Meseta castellana. El razonamiento desarrollado por Giner para caracterizar y comparar esas dos modalidades del paisaje castellano se apoya en la mirada naturalista. Tiene en cuenta los dos componentes naturales que el enfoque geográfico moderno consideraba fundamentales: el relieve y la vegetación. Considera sus formas, sus fisonomías, usando criterios geológicos y botánicos. Las formas del relieve de la Sierra y del llano dependen de la naturaleza de los materiales geológicos y de su consiguiente comportamiento frente a los agentes erosivos. De ahí procede el primer contraste natural importante entre el paisaje de la montaña, que Giner ejemplifica en el conjunto granítico de la Pedriza de Manzanares, y el paisaje del llano, formado por sedimentos recientes. Frente a las formas abruptas del relieve del Guadarrama, aparecen las formas muy suaves del «valle de Madrid», de los llanos de la cuenca sedimentaria, donde Giner dice encontrar uniformidad, pero no monotonía. A ese contraste geológico se añade el botánico, y Giner advierte la correspondencia que existe, en cada caso, entre el relieve y la vegetación. Las diferencias geológicas entre el paisaje de la Sierra y el paisaje del llano aparecen asociadas a diferencias de vegetación no menos importantes. Presta atención a esas diferentes vegetaciones y, al describirlas y comentar su notable contribución fisonómica, aporta una imagen interesante y significativa de los dos paisajes, en la que, con marcado sentido pictórico también en esta ocasión, se refiere a la valoración de las características y las cualidades estéticas y aun morales que ha descubierto en ellos:

En la montaña, severa hasta la majestad, todo es mate y adusto: los líquenes que tiñen el verdoso granito; el monte bajo, cuyo tono apenas templan, allá en la primavera, el morado cantueso, la amarilla flor de la retama, el rojo de tal cual amapola o de las opulentas peonías; el sombrío verdor de los pinos, que se alzan sobre ellos, ora esbeltos y erguidos, ora corpulentos y nudosos, o muertos con el gris de plata de sus ramas 
desnudas, retorcidas y secas. Abajo, en el amplio valle, la luz es más igual; las sombras menos acentuadas, los tonos más ricos y brillantes; los olmos, los chopos, los sauces, los espinos, las zarzas, agotan casi todos los matices del verde, desde el álamo blanco al negro de la encina; y en medio de las tierras sembradas y de las praderas, con su yerba corta, fina y rala, clarean sobre el suelo anchas ráfagas sonrosadas, de una espléndida carnación luminosa (Giner de los Ríos, 2004d: 795).

La montaña y el llano de Madrid son dos ámbitos naturales diferentes, con distintos rasgos geológicos y botánicos, que ofrecen, por tanto, distintas fisonomías, paisajes diferentes. Pero ese contraste natural, fundado en la consideración naturalista, se va a ver muy atenuado, en el razonamiento de Giner, a través de una mirada más subjetiva y más amplia, de signo cultural, que se adentra en el descubrimiento y en la valoración de sus cualidades y significados de índole intelectual, estética y moral. A la explicación naturalista sucede, sin desconectarse de ella, la comprensión cultural del paisaje. Y con ella culmina el modo gineriano de entender la Sierra de Guadarrama y, en general, el paisaje castellano. En la montaña y en el llano cabe encontrar, según Giner, contrarrestando sus diferencias naturales, rasgos cualitativos comunes que permiten igualarlos en términos de valoración cultural. Tales rasgos proceden de la común pertenencia de los dos ámbitos al paisaje castellano. Y es en este terreno de la valoración cultural donde Giner ofrece las reflexiones más originales sobre el paisaje de la Sierra de Guadarrama. Después de referirse al contraste natural entre la montaña y el llano, habla de esas cualidades y valores que lo suavizan, razona sobre su singularidad y su significado, procura aclarar su sentido, y ofrece así una valoración cultural densa y sugestiva de la Sierra de Guadarrama:

Suaviza, sin embargo, este contraste una nota fundamental de toda la región, que lo mismo abraza al paisaje de la montaña que el del llano. En ambos se revela una fuerza interior tan robusta, una grandeza tan severa, aun en sus sitios más pintorescos y risueños, una nobleza, una dignidad, un señorío, como los que se advierten en el Greco o Velázquez, los dos pintores que mejor representan este carácter y modo de ser poético de la que pudiera llamarse espina dorsal de España (Giner de los Ríos, 2004d: 795).

Esta es la esencia de la imagen cultural del paisaje de la Sierra de Guadarrama ofrecida por Francisco Giner y adoptada luego por la Institución Libre de Enseñanza. Atribuyó a ese paisaje un conjunto de cualidades morales —robusta fuerza interior, severa grandeza, nobleza, dignidad, 
señorío, carácter y modo de ser poético- que se correspondían con las cualidades que consideraba propias, distintivas, del pueblo español. La Sierra de Guadarrama no solo ofrecía la más acabada muestra de las cualidades del paisaje castellano del que formaba parte, sino que, además, esas cualidades se correspondían con bastante fidelidad con las que el horizonte historiográfico de Giner y de la Institución atribuyó a Castilla - la Castilla medieval-, y que, a través del protagonismo histórico castellano, contribuyeron de manera decisiva, según ese mismo horizonte, a conformar la comunidad nacional española. Esas correspondencias entre las cualidades del paisaje y los rasgos característicos de la propia historia y de la identidad nacional forjada en ella fundamentaron el significado de la imagen de la Sierra de Guadarrama ofrecida por Giner - y, en general, por el círculo institucionista- Su interpretación hizo de la Sierra de Guadarrama un lugar especialmente importante y significativo. Las cualidades que Giner descubrió allí, y el hondo significado que su visión concedió a tales cualidades, hacen del paisaje de la Sierra de Guadarrama un lugar cargado de valor cultural y simbólico. Ese paisaje entraña así un conjunto de valores - éticos, estéticos e intelectuales- que se corresponden con los que fundamentan el ideario gineriano e institucionista, y pasa a desempeñar por ello un importante papel simbólico en relación con las claves del horizonte liberal y reformista vinculado a ese ideario.

Teniendo en cuenta la valoración natural de la Sierra de Guadarrama promovida por los geólogos de la época, Giner añadió su propia valoración cultural de ese mismo paisaje. Explicación naturalista y comprensión cultural quedaron así conectadas en su visión de ese paisaje. Y existen, como dijimos antes, marcadas analogías entre esas dos valoraciones: la importancia natural de la Meseta central, su decisivo papel en la historia geológica de España, se corresponde con la importancia cultural que adquiere Castilla en el horizonte gineriano, con el singular significado que se atribuye a su participación en la historia de España. Lo mismo sucede, dentro de la Meseta y de Castilla, con la Sierra de Guadarrama: si en términos naturalistas, geológicos, Macpherson había dicho, en 1883, que la Sierra de Guadarrama formaba parte de la «columna vertebral de la Península Ibérica», poco después, en 1886, Giner la consideraba, desde el punto de vista cultural y moral, la «espina dorsal de España». La Sierra de Guadarrama se ve como una atalaya natural y, al tiempo, como una atalaya cultural. Acercarse a ella, andar por sus caminos y ascender a sus cumbres, era para Giner y los institucionistas una forma de elevarse a una mejor comprensión cultural, histórica y nacional, de Castilla y de 
España. «Giner y sus amigos —escribió Joaquín Xirau- emprendieron el camino de la Sierra. Fue uno de sus primeros y grandes descubrimientos. Desde lo alto de la Sierra dominaban Castilla y desde Castilla España entera» (Xirau, 1969: 42). El paisaje de la Sierra de Guadarrama se convirtió así, dentro del horizonte reformista de Giner y de la Institución, en un verdadero símbolo de los valores vertebradores de la propia historia y de la identidad nacional. Y la imagen que ofrecieron de ella fue la más acabada muestra de su modo de entender el paisaje, directamente relacionado con la perspectiva geográfica, que inició en España la trayectoria del paisajismo moderno.

\section{Bibliografía citada}

Altamira, Rafael, «Giner de los Ríos», BILE [Boletín de la Institución Libre de Enseñanza], 39, 659-660 (1915), pp. 59-62.

— «El paisaje y los Parques Nacionales de España», BILE, 45, 736 (1921), pp. 220-222.

Azorín, «Cossío», en Crítica de años cercanos, Madrid, Taurus, 1967, pp. 124-127.

BERDOULAY, Vincent \& Hélène SAULE-SORBÉ, «La mobilité du regard et son instrumentalisation. Franz Schrader à la croisée de l'art et de la science», Finisterra, 33, 65 (1998), pp. 39-50.

BERNALDO DE Quirós, Constancio, «La memoria de Don Francisco Giner», BILE, 46, 740 (1922), pp. 185-187.

- «Recuerdos y enseñanzas de don Francisco Giner», en AA. VV., Estudios jurídicos en homenaje al Profesor Luis Jiménez de Asúa, Buenos Aires, AbeledoPerrot, 1964, pp. 167-203.

BESSE, Jean-Marc, «La fisionomía del paisaje: de Alexander von Humboldt a Paul Vidal de la Blache», en La sombra de las cosas. Sobre paisaje y geografia, ed. Federico López Silvestre, trad. Marga Neira, Madrid, Biblioteca Nueva, 2010, pp. 115-137.

CALDERÓN y ARANA, Salvador, «Ensayo orogénico sobre la Meseta central de España», Anales de la Sociedad Española de Historia Natural, 14 (1885), pp. 131-172.

FOX, Inman, La invención de España: nacionalismo liberal e identidad nacional, Madrid, Cátedra, 1997.

GINER DE LOS RÍOS, Francisco, «Instrucción y educación», en Estudios sobre educación (Obras completas, VII), pról. Ricardo Rubio, Madrid, s. e., 1922, pp. 3-18.

- «La escultura castellana», en Arqueología artística de la Península (Obras completas, XX), pról. Juan Uña, Madrid, s. e., 1936, pp. 63-71. 
— «El espíritu de la educación en la Institución Libre de Enseñanza. A. Discurso inaugural del curso 1880-1881», en Obras selectas, ed. Isabel Pérez-Villanueva Tovar, Madrid, Espasa Calpe, 2004a, pp. 257-274.

— «El Real Sitio del Pardo», en Obras selectas, cit. supra, 2004b, pp. 760-764.

- «Mérida y Badajoz», en Obras selectas, cit. supra, 2004c, pp. 747-759.

— «Paisaje», en Obras selectas, cit. supra, 2004d, pp. 792-801.

— «Santiago de Peñalba», en Obras selectas, cit. supra, 2004e, pp. 786-791.

Humboldt, Alejandro de, Cosmos: ensayo de una descripción física del mundo, 4 vols., trads. Bernardo Giner \& José de Fuentes, Madrid, Imprenta de Gaspar y Roig, 1874-1875.

- Cuadros de la Naturaleza, trad. Bernardo Giner, Madrid, Imprenta y Librería de Gaspar, 1876.

- Tableaux de la Nature, 2 vols., trad. M. Ch. Galuski, intr. Charles Minguet \& Jean-Paul Duviols, Nanterre, Éditions Européennes Erasme, 1990.

LÓPEZ-MORILLAS, Juan, El krausismo español: perfil de una aventura intelectual, México D. F., FCE, 1980, 2. ${ }^{a}$ ed.

- Racionalismo pragmático: el pensamiento de Francisco Giner de los Ríos, Madrid, Alianza Editorial, 1988.

MACPHERSON, José, «Sucesión estratigráfica de los terrenos arcaicos de España», Anales de la Sociedad Española de Historia Natural, 12 (1883), pp. 341-378.

MARTíNEZ DE PISÓN, Eduardo, «El espacio natural de Madrid», Revista de Occidente, 27-28 (1983), pp. 137-150.

- Imagen del paisaje: la Generación del 98 y Ortega y Gasset, pról. Helio Carpintero, Madrid, Fórcola Ediciones, 2012.

Ortega Cantero, Nicolás, Paisaje y excursiones (Francisco Giner, la Institución Libre de Enseñanza y la Sierra de Guadarrama), Madrid, Caja Madrid / Editorial Raíces, 2001.

— «La valoración patrimonial y simbólica del paisaje de Castilla (1875-1936)», Ería, 73-74 (2007a), pp. 137-159.

- «Lectura geográfica del paisajismo literario de la generación del 98», en Valerià Paül i Carril \& Joan Tort i Donada (eds.), Territorios, paisajes y lugares (Trabajos recientes de pensamiento geográfico), Cabrera de Mar, Galerada y Asociación de Geógrafos Españoles, 2007b, pp. 281-297.

- «Los valores del paisaje: la Sierra de Guadarrama en el horizonte de Francisco Giner y la Institución Libre de Enseñanza», en José García-Velasco \& Antonio Morales Moya (eds.), La Institución Libre de Enseñanza y Francisco Giner de los Ríos: nuevas perspectivas. 2: La Institución Libre de Enseñanza y la cultura española, Madrid, Fundación Francisco Giner de los Ríos / Acción Cultural Española, 2012, pp. 673-711.

- «Montañismo y valoración del paisaje: la Real Sociedad Española de Alpinismo Peñalara (1913-1936)», Ería, 95 (2014a), pp. 253-279. 
- «Paisaje, patrimonio e identidad en la conformación de la primera política turística española», Ería, 93 (2014b), pp. 27-42.

Peñalara, «Don Francisco Giner de los Ríos», Peñalara, 2, 15 (1915), pp. 33-34.

REYES, Alfonso, «Un recuerdo de Año Nuevo», en Obras completas, IV: Simpatías y diferencias. Los dos caminos. Reloj de sol. Páginas adicionales, México D. F., FCE, 1956, pp. 393-397.

Xirau, Joaquín, Manuel B. Cossío y la educación en España, Barcelona, Ariel, 1969, 2. ${ }^{\mathrm{a}} \mathrm{ed}$.

Fecha de recepción: 15-6-2015

Fecha de aceptación: 1-12-2015 